\title{
THE ANNUAL GROWTH AND REPRODUCTIVE CYCLE IN FOUR ASCIDIANS
}

\author{
By R. H. Millar \\ The Marine Station, Millport
}

(Text-figs. I-II)

This study was undertaken to increase our very incomplete knowledge of the annual cycle in ascidians.

Berrill (I950) states that 'the age of ascidians, with one exception, is practically impossible to estimate, unless a certain inhabited area is followed closely through seasons and years'. In the present work the method has been to follow certain aspects of the ascidian population of a chosen area for a period of nearly two years. The area was the Old Dock in Ardrossan Harbour, Ayrshire, and the ascidian population contained four species: Diplosoma listerianum (Milne Edwards), Ciona intestinalis (Linnaeus), Ascidiella aspersa (Müller) and Botryllus schlosseri (Pallas). Diplosoma belongs to the order Enterogona, suborder Aplousobranchiata; Ciona and Ascidiella to the order Enterogona, suborder Phlebobranchiata; and Botryllus to the order Pleurogona, suborder Stolidobranchiata. Thus each of the three main suborders is represented, and the four ascidians studied are amongst the commonest British species.

There are three main aspects of the annual cycle: (i) growth, (ii) number and life-span of generations in the year, (iii) sexual reproduction.

Growth. In the simple ascidians Ciona and Ascidiella increase in length of the body suffices as a measure of growth. In the compound forms Diplosoma and Botryllus, however, the case is complicated by the existence of budding. This may involve rapid and almost continual production of new individuals which replace, or live along with, old ones in the colony. It is therefore difficult to find a significant measure of growth in these compound forms. The most convenient measurement, however, is area, since during growth the colonies of both Diplosoma and Botryllus increase in surface area but scarcely at all in thickness.

Number and life-span of generations in the year. The appearance of a new generation and the disappearance of an old one can be detected by inspection of the samples. It is difficult to see the small newly settled larvae, however, and the first evidence of a new generation is usually the presence of small individuals or colonies which have been established for a short but unknown time.

Sexual reproduction. Faunistic lists and papers sometimes give notes on the breeding season of various species, but these are usually generalized 
conclusions based on observations made over a number of years. Also they fail to define the term 'breeding season', which might include a variety of conditions and times from the onset of gonadial development to the settlement of larvae. The period when an ascidian carries eggs and sperm is often considerably longer than the period of their liberation and development in nature. This latter period depends on internal and external limitations on spawning and successful development.

In the present study the progress of breeding was followed by noting the periods when animals carried eggs and sperm, developing eggs, or larvae, and by finding the period during which larvae had settled.

The quantity of eggs and sperm in the ducts can be readily seen in Ciona and Ascidiella. Diplosoma and Botryllus, however, do not have long genital ducts in which eggs and sperm are stored, and in these animals the reproductive condition was assessed by the state of development of gonad, and by the presence or absence of developing eggs and larvae in the zooids or the colony.

\section{The ARea Studied}

The Old Dock, Ardrossan, is a semi-tidal sea-water dock, the water-level in which is controlled by sea gates. The amount of interchange of water between the dock and the sea is uncertain and variable, and depends partly on the traffic of ships through the gates. The predicted depth at H.W.o.s.T. is I9 ft. and the area of the dock is 4.23 acres. The walls, which are of stone, are vertical and form the substratum to which Ciona and Ascidiella are attached. Diplosoma and Botryllus are generally fixed to the test of the simple ascidians.

\section{METHODS}

Samples were collected by scraping the walls of the dock at intervals throughout I950 and I95I.

The size of samples varied with the availability of material, which depended partly on the time of year and partly on the water-level in the dock. The number of specimens measured $(N)$ is shown on histograms of size distribution where percentages are used. The animals were narcotized with menthol, fixed in the expanded state in strong formalin and stored in weak formalin. Measurements of length in Ciona and Ascidiella were made to the nearest I mm. The colonies of Diplosoma and Botryllus were carefully removed from the substratum (generally the test of Ciona or Ascidiella), placed flat on the glass negative-carrier of a photographic enlarger, covered with a glass slide, and inserted in the enlarger. The outline of the projected image was traced on squared paper and the area of the colony calculated from the outline tracing.

Specimens of Ciona and Ascidiella were dissected and the genital ducts examined for eggs and sperm. A number of zooids were removed from each 
colony of Botryllus and examined for the presence of gonad, developing eggs and larvae. In the colonies of Diplosoma zooids were examined for eggs, and the common test for developing eggs and larvae. In each sample of Botryllus and Diplosoma about twenty colonies were thus examined. Pieces of several colonies of the compound forms, in each sample taken during I950, were sectioned to confirm the results of dissection.

\section{Ascidiella aspersa (Müller)}

Growth, number of generations in the year, and life-span.

The length of the specimens was taken as a measure of their size. In Fig. I a series of histograms shows the distribution by size of $A$. aspersa in the samples taken in I950 (left) and I95I (right).

The sample of 24 January I950 showed two populations, one whose body length had the mode about $25 \mathrm{~mm}$., and the other with the mode about $50 \mathrm{~mm}$. The population of small animals represented rather more than $80 \%$ of the sample and consisted of animals that settled as larvae in the previous summer (I949). The remaining population, of large specimens, was rather less than $20 \%$ of the sample and represented animals that settled as larvae in the summer of 1948 .

Between January and April there appears to have been some growth of the smaller animals of the I949 group, but less amongst the larger ones. During this period the percentage of the total sample represented by the 1948 group gradually decreased until in April it accounted for only about $2 \%$ of the total sample. Thus, although a large part of the I 948 group had perhaps died before the first sample was taken in I950, it was in the months from January to April that this group virtually disappeared.

Growth for the I950 season became important between 2I April and 24 May and continued at a high rate until about the middle of June. From then until the middle of July growth was considerably slower, at least amongst the larger individuals.

The sample of I4 July gave the first evidence of the new generation, and from this time until about the end of September growth of animals of this I950 group continued. During the same period there was no appreciable growth in specimens of the I949 group, and after the end of September there appeared to be no further growth in either the I949 or the I950 group.

On 27 November about $20 \%$ of the sample belonged to the I950 group and about $80 \%$ to the 1949 group.

It is evident that in 1950 only one new generation of $A$. aspersa was produced, and that this was established mainly in July but possibly also somewhat earlier and later.

The samples of I I January and I3 April I95I are too small to be very useful but tend to confirm the results of 1950 , that at this early period of the year 


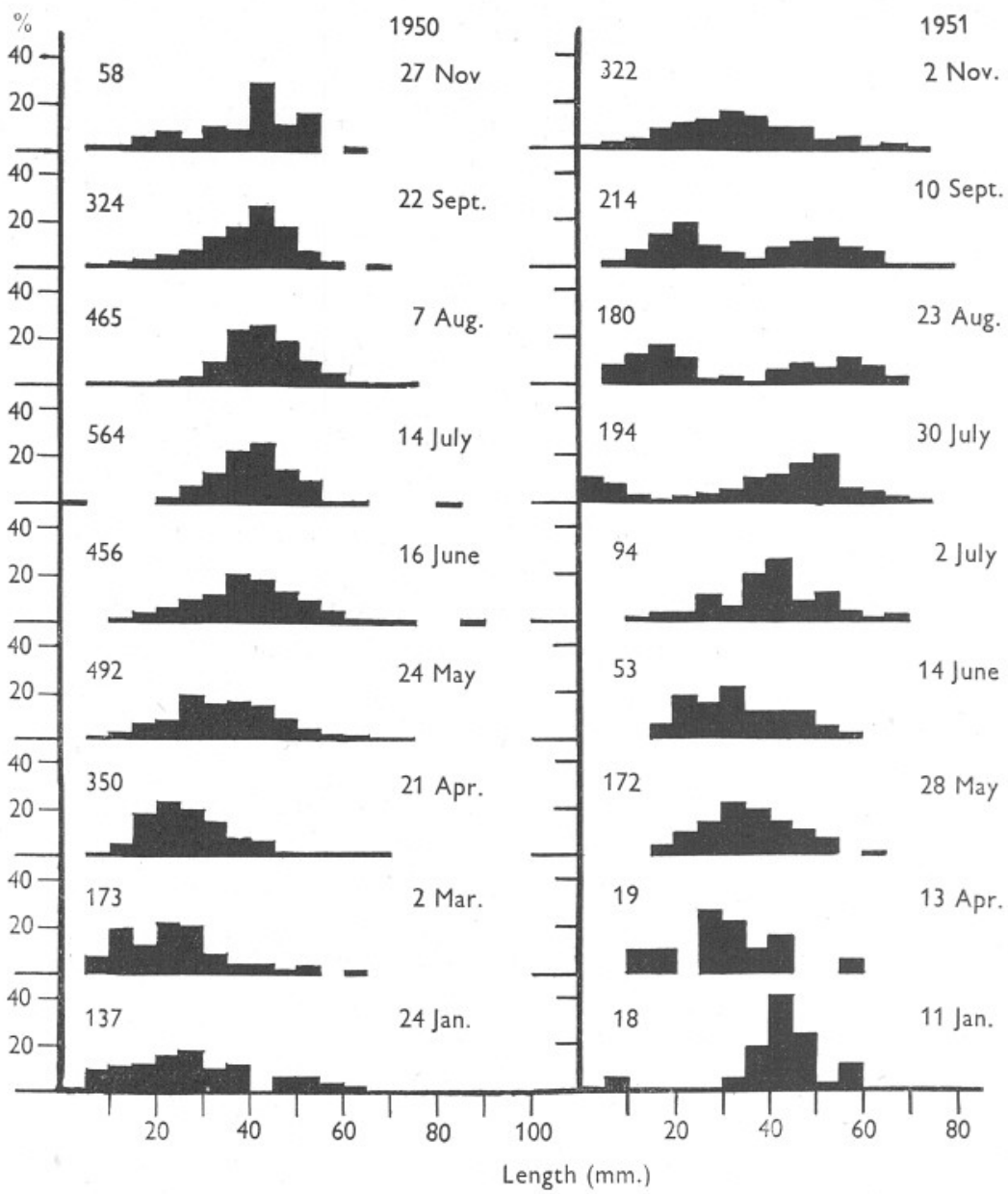

Fig. I. Size-frequency histograms (in percentages) of Ascidiella aspersa in 1950 and $195 \mathrm{I}$. The figures on the left of each histogram denote the number of specimens in the sample.

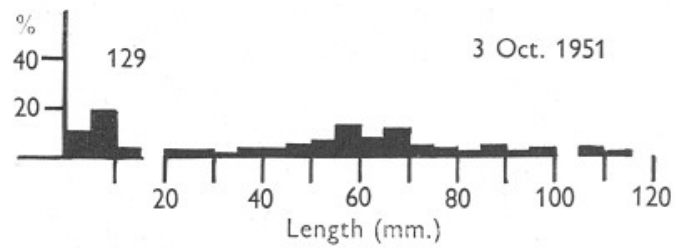

Fig. 2. Size-frequency histogram of $A$. aspersa on 3 October 1951, from Loch Sween, Argyll; as in Fig. I. 
the population represents two year-groups. The animals of these two groups had settled as larvae in the summers of 1949 and 1950 respectively. The samples also suggest that many of the larger individuals (i.e. of the I 949 group) died between II January and I3 April.

The figures for the rest of I95I follow the same general pattern of growth and settlement that was found in I950. In I95I, however, no growth was apparent until after I4 June, whereas in I950 the animals had grown considerably before 24 May. On 2 July no newly settled individuals were found. They were present on 30 July, however, but in the sample of 23 August and in all later samples none was found. The period of larval settlement in I95I therefore started between 2 July and 30 July and finished between 30 July and 23 August.

Animals of the new, I95I, group continued to grow from the end of July until some time between Io September and 2 November, but during this period the animals of the old, I950, group made no measurable growth. Only one new generation was established in I95I.

A single sample of $A$. aspersa was taken from Loch Sween, Argyll, on 3 October I95I to provide a comparison with the autumn samples from Ardrossan. Fig. 2 shows the size distribution of the specimens. It appears that here also the population represents two clearly separate age-groups, the smaller animals, up to about $15 \mathrm{~mm}$. long, belonging to the $195 \mathrm{I}$ settlement and the larger ones belonging to the I950 settlement. The size distribution of this sample suggests that the general pattern of growth and reproduction may be similar over much of the west coast of Scotland. The main differences in the sample from Loch Sween, as compared with autumn samples from Ardrossan, are: (i) the smaller size of the individuals of the I95I group, and (ii) the larger size of those of the I950 group.

These features may result from a later breeding season and more favourable conditions for growth in Loch Sween.

It may be deduced, from the samples of these two years, that the life-span is of the order of I8 months, extending approximately from the middle of one summer until the winter of the following year. A. aspersa in this area is essentially an annual, a conclusion which Hŭus (I937) also reached for this species on the Norwegian coast.

\section{Sexual maturity}

Fig. 3 shows, for each of the size-groups, the percentage of sexually mature animals in the samples of I950. The upper half $(S$.$) refers to sperm, and the$ lower half $(E$.$) to eggs, in the genital ducts. Sexual maturity is here taken to$ mean the presence of sperm or eggs in the genital ducts, irrespective of the quantity. The figures show two features:

(I) $A$. aspersa is hermaphrodite, but is slightly protandrous, as the sperm duct starts to fill before the oviduct. The $20-25 \mathrm{~mm}$. group shows this 
protandrous tendency most clearly. This finding contradicts Herdman's (I899) general statement that Ascidia is protogynous.

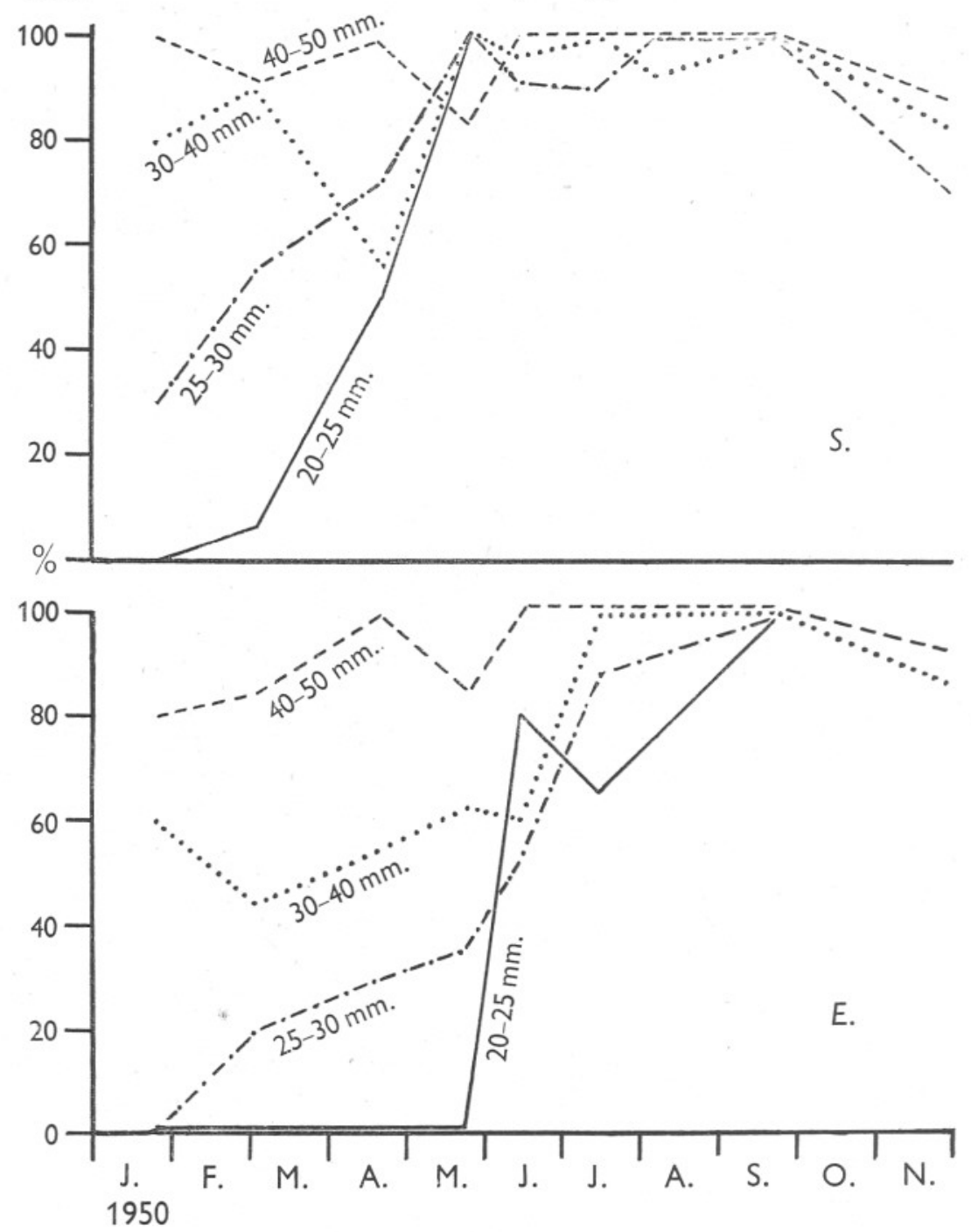

Fig. 3. Relations between the time of year and the percentage of specimens of $A$. aspera with sperm $(S$.$) and eggs (E$.$) in the ducts, for each of the size groups 20-25,25-30,30-40$ and $40-50 \mathrm{~mm}$., during 1950.

(2) Sexual maturity depends primarily on the size of the animal. When an individual reaches a certain critical size sperm begins to appear in the sperm duct and at a slightly larger size eggs pass into the oviduct. The critical size, however, changes during the year. Thus practically all individuals over 
$40 \mathrm{~mm}$. in length are mature as male and female throughout the year. In the $30-40 \mathrm{~mm}$. group over $80 \%$ are mature as males during the whole year, but from January until June only about $40-60 \%$ of this group are mature as females. In the $25-30 \mathrm{~mm}$. group there is a steady rise in the proportion with sperm, from January to May, when all have become mature; there is a similar but more gradual rise in the proportion with eggs. The $20-25 \mathrm{~mm}$. group shows the sharpest rise in the percentage mature, both as male and as female, between January and June. In June sperm generally starts to fill the sperm duct when the animal is slightly under $25 \mathrm{~mm}$. long, and eggs pass into the oviduct when the animal is rather less than $30 \mathrm{~mm}$. long. This difference of about $5 \mathrm{~mm}$. in the critical body length for male and female maturity is supported by observations made on a sample of $A$, aspersa taken on 20 August I948 from a tufnol plate suspended in the waters of Loch Sween, Argyll. Fig. 4 shows, for this sample, the relation between the body length and the presence or absence of sperm and eggs in the ducts. Incidentally, the animals in Loch Sween became mature at a smaller body size than did those in any of the samples from Ardrossan. This may have resulted from environmental differences like those which appear to have influenced the Ardrossan population during the course of the season.

The time of settlement, growth rate, critical body length and life-span were such that a sample taken at Ardrossan at any time of year contained a large proportion of mature individuals. In the sample of 27 November I950, for example, most of the 1949 group carried eggs and sperm, and the larger members of the I950 group also did so. Of this population, however, the I949 group died before spawning again, in I95I. Its place was taken by the I950 group, which spawned in the summer of I95I. In the area studied, therefore, it appears that a given year group of $A$. aspersa has only one spawning season, and that is in the year after it settled as larvae.

\section{Ciona intestinalis (Linnaeus)}

\section{Growth, number of generations in the year, and life-span}

Ciona is more difficult to measure than $A$. aspersa because it is more contractile and because its body form varies more according to its contact with the substratum. It was therefore essential to narcotize the animals thoroughly before fixing and measuring them. Another difficulty was the limited supply of animals necessitating small samples.

Fig. 5 is a series of histograms showing the distribution by size of Ciona taken at intervals throughout 1950 and part of I95I. The samples of January, March and April I950 showed two populations, but these were not clearly distinguishable. The numerically larger population had a small body length, and most specimens were between Io and $30 \mathrm{~mm}$. long. These animals had settled as larvae in I949. The other population had a body length ranging 


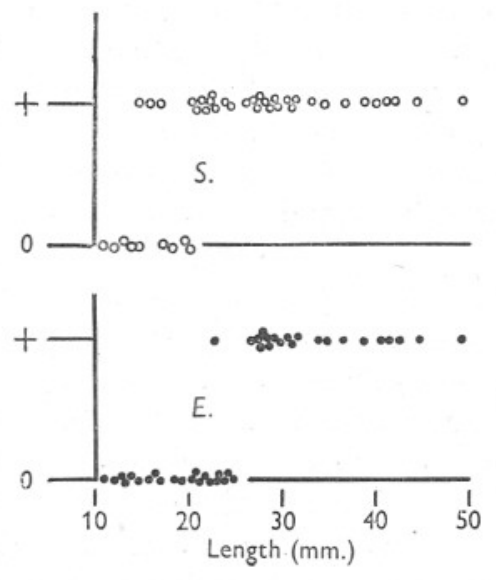

Fig. 4.

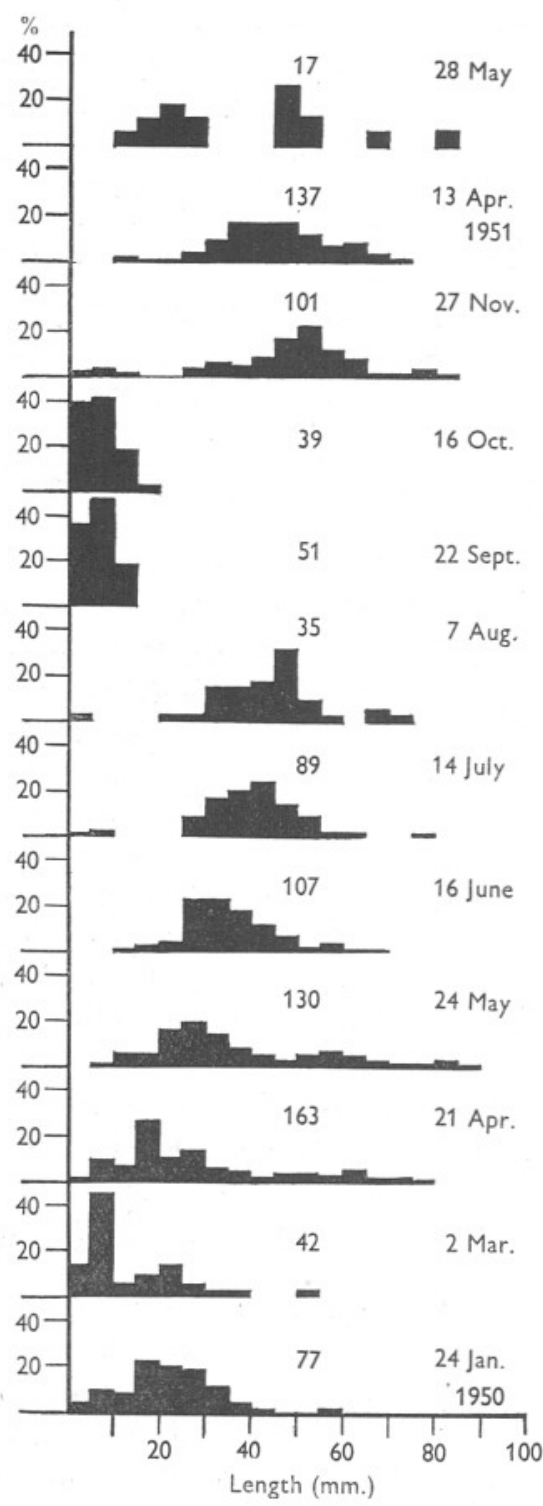

Fig. 5 .

Fig. 4. Relation between the body length and the presence or absence of sperm and eggs in the ducts of $A$. aspersa, in a sample from Loch Sween, Argyll, taken on 20 August 1948. $S$. sperm in duct; $E$. eggs in duct.

Fig. 5. Size-frequency histograms (in percentages) of Ciona intestinalis in 1950 and early $195 \mathrm{r}$. The figures denote number of specimens in the sample. 
approximately from 50 to $70 \mathrm{~mm}$. These animals had settled as larvae in I948. The I949 group tended to be bimodal, suggesting that during the previous year settlement may have been more intense at two periods separated by an interval when fewer larvae settled. Little or no growth was evident between January and 2I April, but during May, June and July the animals of the I949 group grew considerably. By the end of May the bimodal tendency could no longer be detected in the I949 group, the smaller individuals having grown faster than the larger ones. The animals of the I948 group made little, if any, growth between May and July, as most of them had already reached their maximum size. There are, unfortunately, gaps in the records of the 1949 group during September and October, as continued sampling had reduced the stock. It was not until November that numbers of this population were found in a different part of the dock. These gaps in the records, however, are not serious, since it is obvious from the histograms for August and November that we are dealing with the same year-group. Between August and November there appears to have been little growth within the I949 group.

It is more difficult to assess the proportion of the I948 and I949 groups in each sample of Ciona than in the samples of Ascidiella, and to say when the I 948 group died out. Most of the I 948 group had apparently disappeared before the first sample was taken in 1950, but a few were certainly still present in the sample of 24 May.

The first evidence of the I950 settlement was in the sample of I4 July, in which a few young specimens were found. As one of these was already $7 \mathrm{~mm}$. in length, settlement of larvae must have started a few weeks before this sample was taken. It was difficult to find numbers of the I950 group sufficient to give a clear idea of their growth rate. This may have been due partly to depleted breeding stock and partly to an unsuccessful breeding season. The similarity between the histograms for 22 September and I6 October suggests that growth of the members of the I950 group did not continue after the end of September.

Only one generation of Ciona was produced in I950 in the area studied. Settlement of larvae appears to have started in July and continued through August and probably into September, as at the end of this month specimens of only $2 \mathrm{~mm}$. length were still being found. The presence of individuals in the $0-5 \mathrm{~mm}$. group during October and November does not necessarily indicate further settlement. As growth had already stopped for the year individuals which settled in September could still be in the $0-5 \mathrm{~mm}$. group throughout the winter. This suggestion is supported by the presence of specimens only 3 and $4 \mathrm{~mm}$. long in the samples of January and March I950.

In I95I samples were obtained up to 28 May after which the population was apparently so depleted that only occasional specimens were taken. These 
few samples, however, tend to confirm two features of the I950 sampling: (i) growth of the animals of the recent year-group (in this case the r950 group) started before the end of May; and (ii) most of the remaining animals of the previous year-group (in this case the I949 group) died before the end of May.

The general pattern of growth, reproduction and replacement of generations in Ciona was very like that found in Ascidiella. Individuals settled in the summer, grew until autumn, resumed growth in the following spring, spawned in the summer of that year, and died in the following winter. They are therefore essentially annuals, although they may be 18 months old or somewhat more when they die.

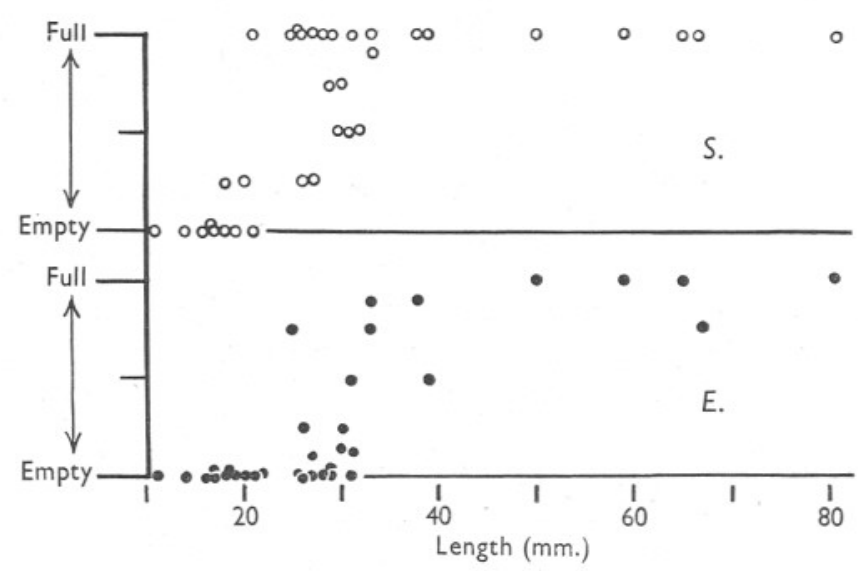

Fig. 6. Relation between the body length and the quantity of sperm (S.) and eggs $(E$.$) in$ the ducts of $C$. intestinalis in the sample taken on 24 May 1950 .

Orton (19I4, 1920) found that in the Plymouth area Ciona breeds from April to November, producing two or three generations in the year. Hŭus (1937) states that on the Norwegian coast Ciona is sexually mature within its first year of life and dies off after breeding, having a life of about one year. In Naples, Lo Bianco (1909) records Ciona as breeding throughout the year. Rünnstrom (1936) found that Ciona has three physiological races which breed within different temperature ranges. On the west coast of Norway he found Ciona to spawn from May to August, after which the old generation dies off. It is replaced by the new one which becomes sexually mature by the end of August but does not, apparently, produce a further generation: eggs and sperm may be shed from October to December but fail to develop.

The population of Ciona studied in Ardrossan Old Dock resembles the animals of the Norwegian west coast in breeding behaviour and the annual cycle of generations, although differing somewhat in the timing of events and speed of processes. 


\section{Sexual maturity}

Fig. 6 shows the relation between the length of the body and the quantity of eggs and sperm in the genital ducts of a number of specimens of Ciona from the sample of 24 May I950. The remaining samples were not examined in detail, but the same general relations were found.

Ciona, like Ascidiella, is a slightly protandrous hermaphrodite. Sperm starts to enter the sperm duct at a critical body length and eggs appear in the oviduct later, when the body length is somewhat greater. Fig. 6 suggests that the critical body length for the appearance of sperm in the duct is about $25 \mathrm{~mm}$. and of eggs in the oviduct about $30 \mathrm{~mm}$., in the sample examined.

\section{Growth Diplosoma listerianum (Milne Edwards)}

The area of the colonies was measured as described on p. 42. In Fig. 7 a series of histograms shows the distribution by area of the colonies taken at intervals throughout 1950 and I95I.

All colonies of the sample of January I950 originated from larvae that settled in I949. Most of the colonies of this sample were less than $50 \mathrm{~mm} .^{2}$ in area and the largest was $170 \mathrm{~mm} .{ }^{2}$. Growth in 1950 started between 2 March and 2I April and continued until about the end of May. Maximum size appears to have been reached by I6 June, when a number of colonies were between 1000 and $1500 \mathrm{~mm} .^{2}$ in area.

In the sample of I4 July a few colonies showed degeneration of the zooids, but it was in the sample of 7 August that this process first became widespread. Food was not seen in the gut of zooids in August, and this is taken as another sign of lowered vitality. By 22 September I 950 most of the 1949 generation of colonies had died and many of those remaining were degenerate.

New colonies of the I950 generation were first observed in the sample of I4 July but were few. The new colonies were more common on 7 August. On 22 September most of the sample, and on 27 November all of it, consisted of the new, I950, generation.

Appreciable growth of the newly established colonies took place before 22 September.

The pattern of growth and replacement of generations in I95I was in general similar to that observed in I950. In I951, however, spring growth up to 28 May was much less than spring growth during a corresponding period of I950 (up to 24 May). A similar feature was observed in the growth of Botryllus (see p. 58). In the autumn of I95I colonies of the new generation continued to grow after Io September, as shown in Fig. 7, bottom right.

\section{Sexual reproduction}

Asexual reproduction by budding leads to an increase in the size of the colony and not to the founding of new colonies, which is the function of 


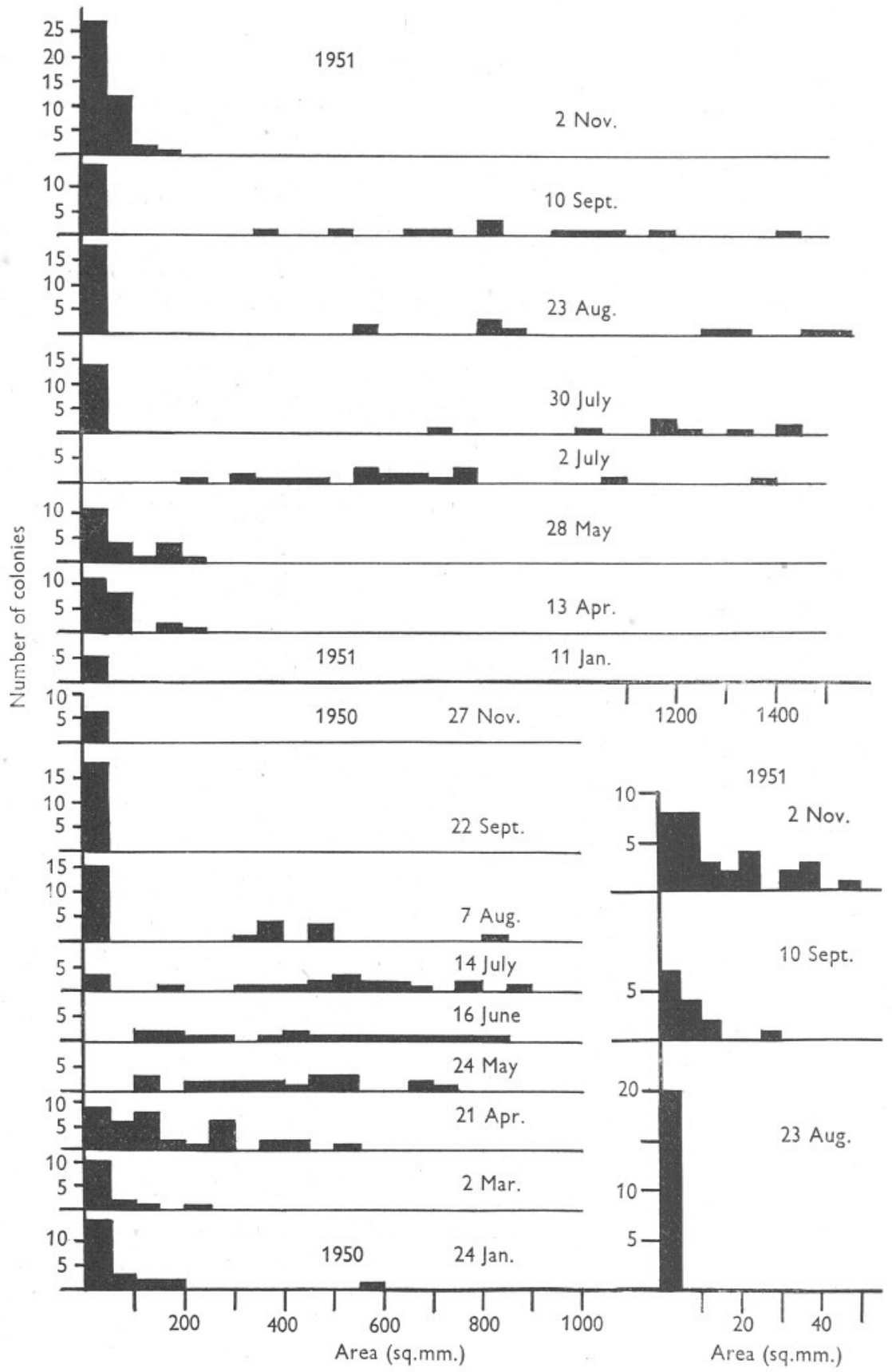

Fig. 7. Size-frequency histograms (by area) of Diplosoma listerianum in I950 and I95I. The smallest specimens for three successive dates are further analysed in the inset at right bottom. 
sexual reproduction. During sexual reproduction budding was reduced but it continued long after the onset of gonadial development and egg production. It only ceased, presumably, when there was serious competition for raw materials between the sexual and the asexual processes. Huxley (I92I) and Berrill (I935) have drawn attention to this competition in colonial ascidians.

The ovary (Fig. 8, Ov.) of Diplosoma lies in the lower part of the abdomen, and shows only a few large eggs at any time. As the season advances the eggs enlarge and pass singly from the abdomen down into the basal layer of test. Lahille (I890) states that the egg is fertilized only after breaking through the body wall and coming to lie in the common test, but Berrill (I950) maintains that it is fertilized before leaving the abdomen. Development to the larval stage certainly takes place within the common test.

Fig. 9 summarizes the conditions found in the samples of Diplosoma throughout I950, and records the percentage of colonies with: (A) neither eggs nor larvae in zooids or test; (B) eggs in zooids but not in test; (C) eggs in zooids and eggs or larvae in test; (D) eggs or larvae in test but no eggs in zooids; (E) larvae.

The graphs indicate the progress of breeding activity.

January to March was a period of sexual inactivity, during which colonies

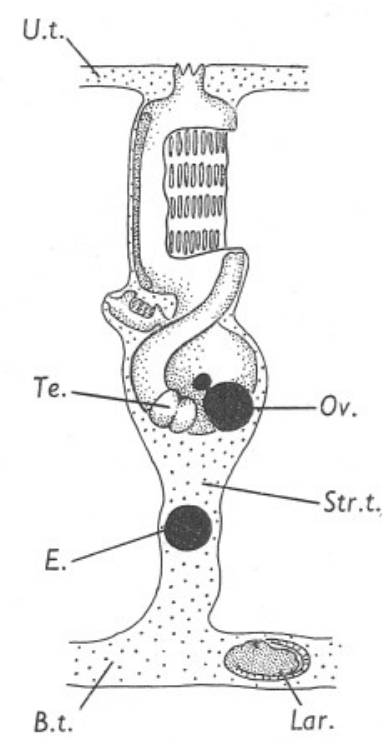

Fig. 8. Zooid of D. listerianum within the common test of the colony. B.t. basal layer of common test; $E$. egg; Lar. larva; Ov. ovary; Str. $t$. strand of common test securing zooid to basal layer; Te. testis; U.t. upper layer of common test. of the 1949 generation had eggs neither in zooids nor in test. Some colonies, however, showed eggs or larvae, or the degenerate remains of these, in zooids or test. These eggs and larvae appear to be residual products which failed to develop completely and escape during the previous year. They may be regarded as abnormal, as they were probably held within the incompletely disintegrated basal layer of colonies of the 1948 generation. This condition was more common in I95I (see p. 55).

Between the March and April samples there had been an increase in the proportion of colonies with eggs in the ovaries, and this period marks the onset of sexual activity for the year. During May there was a sharp rise in the percentage of colonies with eggs in the common test as well as in the zooids, indicating a large-scale passage of eggs from the zooids down into the common test. It was on 24 May that the first developing embryos were seen. All 
colonies examined in the middle of June had eggs in the zooids and also eggs or larvae in the test. Egg production started to diminish in July, as indicated by a slight drop in the percentage of colonies with eggs in zooids as well as test. Between mid-July and early August the ovary became inactive and the production of eggs ceased. In the July and August samples all colonies examined had larvae, and some had developing eggs, in the test.

The first signs of exhaustion resulting from breeding activity were seen in July, when a few colonies were found with degenerating zooids; in August this condition was common.

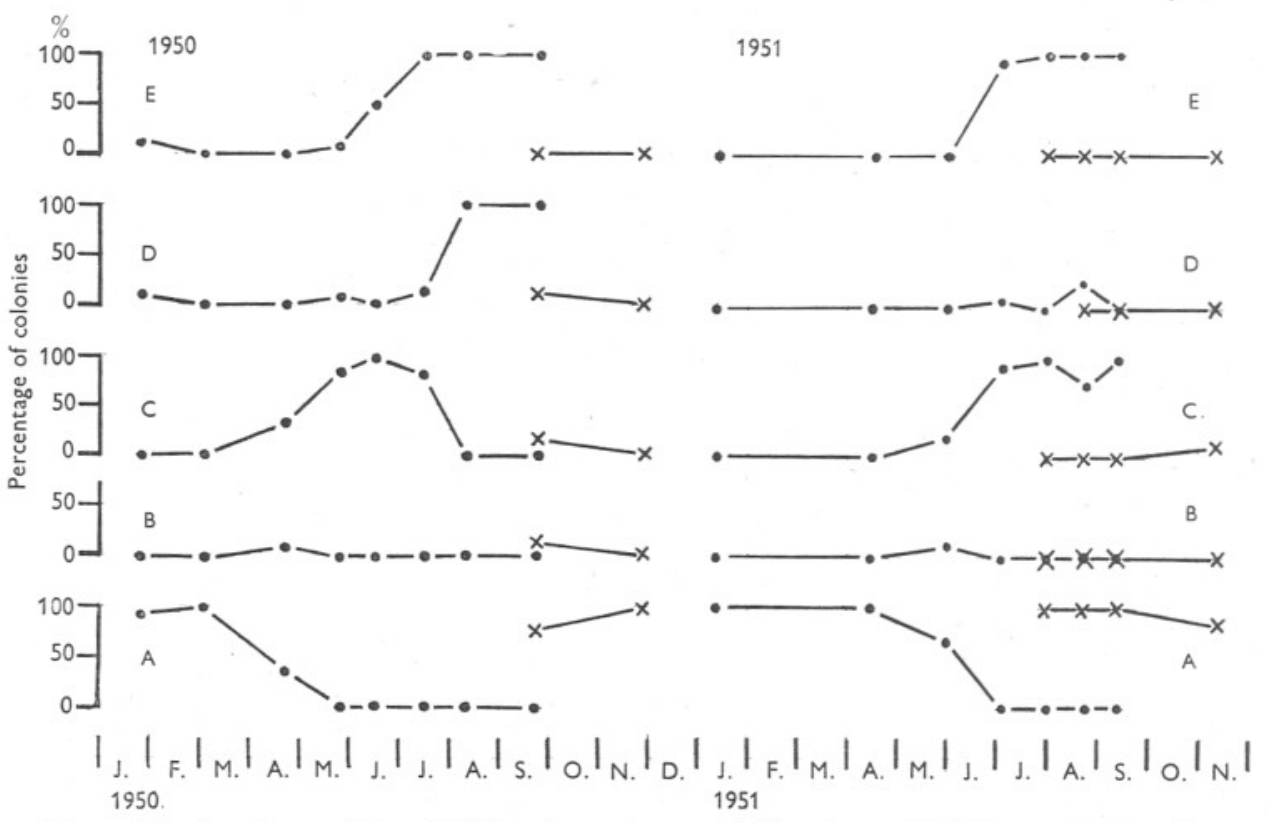

Fig. 9. The breeding activity of $D$. listerianum in 1950 (left) and I95I (right). A, colonies with no eggs and no larvae in zooids or test; $\mathrm{B}$, colonies with eggs in zooids but not in test; C, colonies with eggs in zooids and eggs or larvae in test; D, colonies with eggs or larvae in test but no eggs in zooids; $\mathrm{E}$, colonies with larvae.

Larval settlement was indicated by the presence of young colonies in the samples of I4 July, 7 August and 22 September. The settling period was not determined more precisely and may not have extended into the second half of September. It is perhaps significant that the settling period coincided with the period during which the old colonies disappeared, and it may be that the larvae are liberated only with the disintegration of the breeding colonies. Berrill (1950), on the other hand, states that the active tadpoles escape from the test matrix to the common cloacal cavities of the colony and thence to the exterior. Many of the Ardrossan colonies examined, however, showed areas of degenerating zooids below which larvae were still retained in the 
common test. The existence of many composite colonies (see below) in November I95I also indicates prolonged retention of larvae in the test, even after the disappearance of the parent zooids.

The young colonies grew and, as the September sample showed, some of the zooids produced eggs. Developing larvae were also found in a few young colonies in September. That some of these young colonies may have given rise to a second generation is suggested by the presence of a few two-zooid colonies in late November. It is possible, however, that these small colonies in November came from late larvae of the old colonies.

A study of the breeding activities of Diplosoma during I95 I confirmed the general picture gained in 1950 , as seen from the right-hand part of Fig. 9. It appears that the onset of breeding was later in I95I than in I950. This difference is shown in the later disappearance of the non-breeding condition (A), the later appearance of eggs in the zooids (B), the later rise in the percentage of colonies with eggs in both zooids and test (C), and the later transition of colonies to the final breeding stage (with eggs or larvae in the test only, D). By comparing the dates in 1950 and I95I on which the same percentage of the samples was in a particular reproductive state, we can estimate the lateness of the I95I season. The lateness was of the order of 6 weeks.

One other feature of the I95I graphs deserves comment: this is the much smaller percentage of colonies during August with eggs or larvae in the test only, compared with the I950 figures. The lower percentage in I95I was due to the later degeneration of zooids, because as long as the zooids remain healthy some at least continue to produce eggs.

The delayed decay of the old colonies in the autumn of I95I gave rise to another interesting condition: this was the formation of composite colonies. A composite colony consists of the basal layer of test of an old colony with its larvae still enclosed, and zooids of the new generation derived from these larvae which have metamorphosed in situ. No zooids of the old generation remain.

Later breeding in I95I may have resulted from later growth, which was observed to occur, but more probably some environmental factor, such as lower water temperature, retarded both activities.

\section{Number of generations}

In the area studied Diplosoma produced, both in I950 and I95I, one principal generation and possibly a minor one in I950 late in the season. Orton (I9I4) states that, in the Plymouth area, the species passes through 'at least two crops in a year' and three or more in favourable seasons. Once he got larvae from a colony aged not more than 3 weeks and 5 days.

The rate of development of the colonies and the time at which larvae are liberated are the factors determining the number of generations per year. 
These factors are greatly influenced by local and seasonal conditions. Berrill's (1950) statement that 'breeding occurs throughout the year' is too general, although no doubt true in specially favourable conditions.

\section{Growth Botryllus schlosseri (Pallas)}

The colonies of Botryllus were removed from the substratum and their area measured by the method described on p. 42. Fig. Io gives a series of histograms showing the distribution by area of the colonies taken at intervals throughout 1950 and $195 \mathrm{I}$.

In January 1950 the sample of Botryllus represented a single year-group, consisting of colonies that had been established in 1949. Many colonies were under $25 \mathrm{~mm} .{ }^{2}$ in area and had only one system of zooids. The few large colonies in this sample were between 200 and $300 \mathrm{~mm} .{ }^{2}$ in area and these had ten to twelve systems of zooids. The onset of growth for the 1950 season occurred between 2 March and 2I April. In the April sample most specimens lay within the $25-30 \mathrm{~mm} .{ }^{2}$ group and these colonies had two or three systems of zooids. Large colonies between 500 and $750 \mathrm{~mm} .{ }^{2}$ had fifteen to twenty systems. Growth continued during May and by 16 June maximum size had, in general, been attained. Only two colonies in the June sample had as few as six systems of zooids and the majority had fifteen to twenty or more systems. One or two of the large colonies showed some degeneration in June, the first to be observed in 1950 .

The sample of I4 July showed two important features: (I) the first new colonies resulting from larval settlement, and (2) considerable degeneration in the large colonies.

The new generation was represented by two small colonies, each of a few zooids arranged in one system.

By 7 August the change of generations was almost complete, only one colony of forty-three examined belonging certainly to the 1949 generation. The remainder of this sample consisted of small colonies, mostly of one system, but a few of two, three, or four systems. Two single zooids were found, recently metamorphosed from settled larvae. On 22 September no colonies of the 1949 generation were found.

A more detailed comparison of the samples of 7 August, 22 September, and 27 November 1950 shows that the young colonies grew during late summer and autumn (Fig. Io, inset). Table $\mathrm{I}$ suggests that this growth took place without an increase in the number of systems per colony.

It can be seen by inspection of the histograms for I95I that they agree fairly well with those for 1950. In the sample of January I95I all colonies belonged to the 1950 generation. Growth had begun by I3 April and continued until June. Early in July degeneration of colonies had started but was most noticeable at the end of that month. The first new colonies, of the I95I 


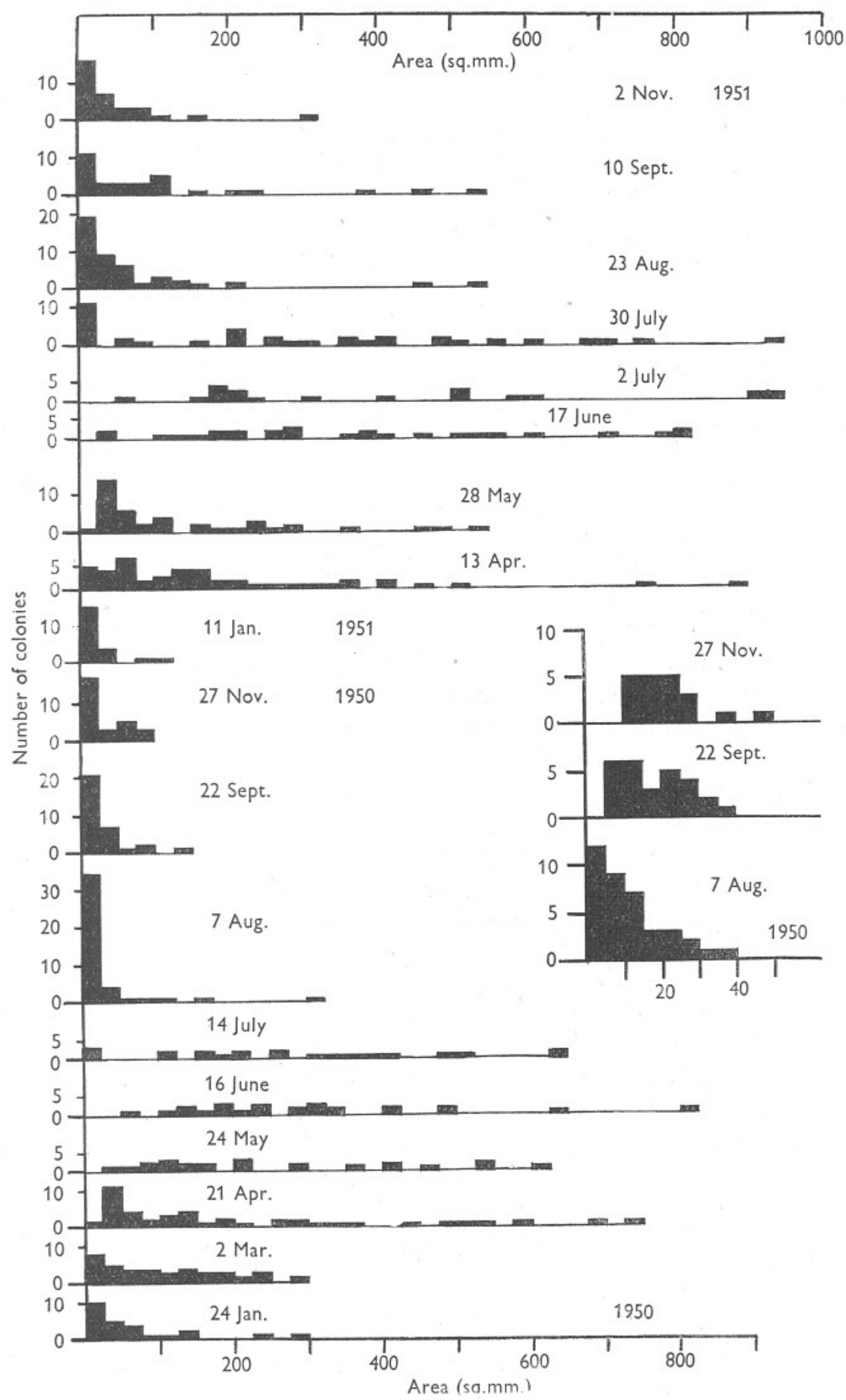

Fig. 10. Size-frequency histograms (by area) of Botryllus schlosseri in 1950 and 1951. The smallest specimens for three successive dates in 1950 are further analysed in the inset on the right. 
generation, were seen at the end of July, and by 23 August most of the sample consisted of this new generation.

Although the general pattern of growth was similar in the two years, the onset of spring growth was later in I95I than in I950. This can be seen by comparing the histograms for approximately corresponding dates in the two years, viz. 2I April I950 and I3 April I95I; 24 May I950 and 28 May I95I. A similar retardation of growth was noticed in Diplosoma.

\section{TABLE I}

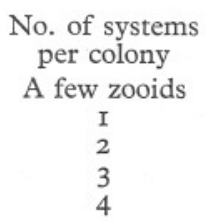

$\begin{array}{cccc}\text { TABLE I } & \text { No. of colonies } \\ \text { 7. viii. } 50 & \text { 22. ix. } 50 & \text { 27. xi. } 50 & \text { I I. i. 5 I } \\ 2 & 0 & 0 & 0 \\ 24 & 20 & \text { I5 } & \text { I6 } \\ 9 & 5 & 3 & \text { I } \\ 4 & 2 & 4 & 2 \\ \text { I } & 2 & 5 & 0\end{array}$

\section{Number of generations}

The population of Botryllus passed through one generation in each of the years studied, and it seems unlikely that even the earliest new colonies were able to produce many larvae that settled to form a second new generation. Orton's (I9I4) findings that Botryllus, like Diplosoma, has at least two crops in the year applies to the Plymouth area.

\section{Sexual reproduction}

Berrill (I94I, I947, I950) has described the process of bud formation and gonad development in Botryllus and Botrylloides. He has shown that the sex of the gonad and the state of development that it attains depend on the size of the bud bearing the gonad. Berrill (I935) also found that sexual and asexual reproduction take place simultaneously, but that budding may be relatively subdued during sexual reproduction.

The samples of Botryllus were examined, and Fig. II records the percentage of colonies in each sample during I950 and I95I with: (A) neither eggs nor larvae, (B) gonads, (C) large or developing eggs, (D) larvae.

Gonads were visible in a low percentage of colonies in January and March, and sections showed small developing ovaries and testes in some zooids and buds. No larvae were present in these months and only a few large eggs were found in one colony in March. Gonadial development was rapid during March and early April, but still there were only a few large eggs, and no larvae. The percentage of colonies with visible gonads was highest in May and June, dropped sharply to the level of July, and by late September had returned to the winter level. The percentage of colonies whose zooids had large or developing eggs followed a rather similar curve, but reached a high value for a shorter period. 
Larvae were first found in the sample of 24 May, when some colonies had fully developed larvae and others had tailed but still incomplete larvae. The percentage of colonies bearing larvae continued to rise in June and reached a maximum in July, after which there was a rapid decrease. A few larvae were still found until the end of November. The first new colonies of the year appeared in the sample of I4 July and their number increased in August, but there was no evidence of very recent settlement in the sample of 22 September.

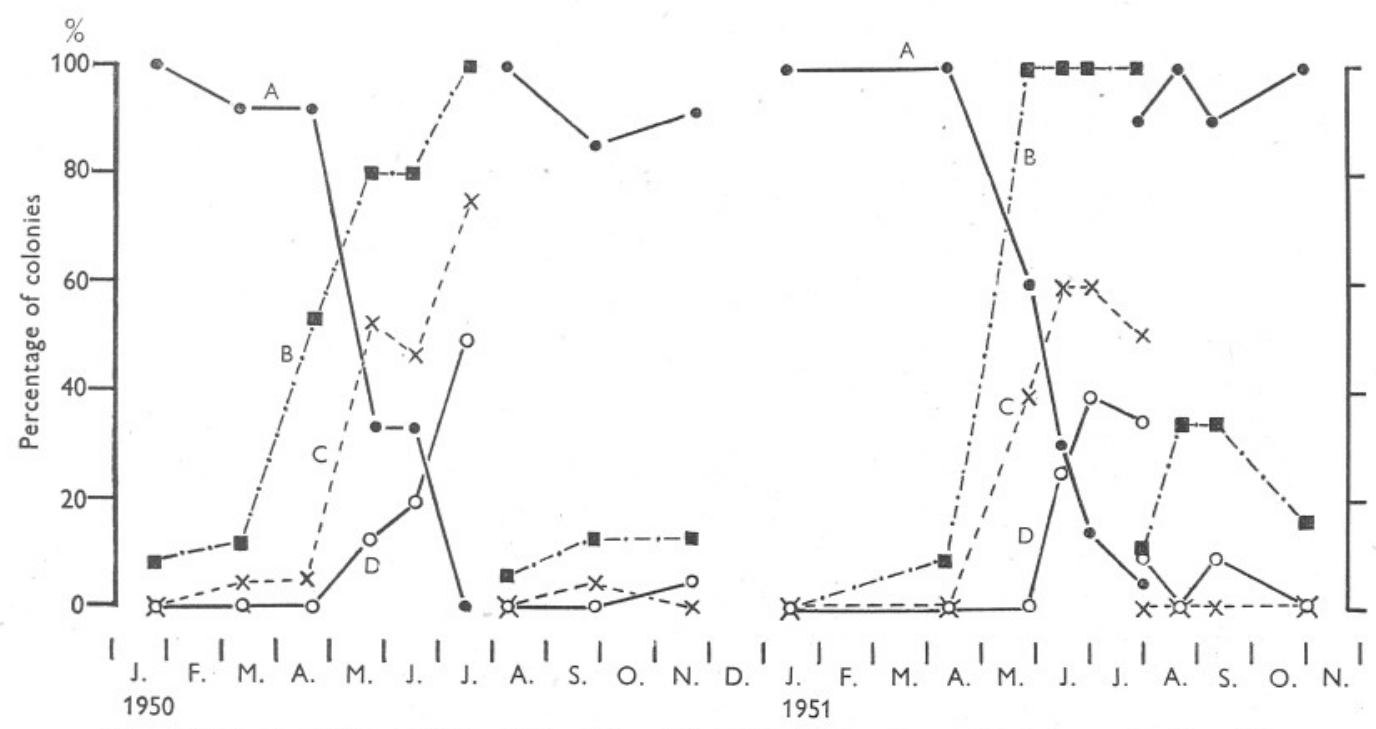

Fig. II. The breeding activity of B. schlosseri in I950 (left) and I95 I (right). A, colonies with no developing eggs and no larvae; B, colonies with visible gonad; C, colonies with developing eggs; D, colonies with larvae.

In I95I the cycle of breeding in Botryllus was similar to that in I950, but was later in most of its stages. This appears from a comparison of the graphs, for the two years, of the percentage of colonies with (I) gonad, (2) developing eggs, and (3) larvae. The period of larval settlement, however, was rather similar, starting some time between 2 July and 30 July, and extending certainly until the end of August and perhaps into September.

In both years the proportion of Botryllus colonies with larvae reached, at its maximum, only about $30-40 \%$ of the total examined. This is in marked contrast to the condition in Diplosoma, where 100\% of the colonies examined in July and August had larvae. The probable explanation of the difference lies in the fact that the larvae of Botryllus develop in the atrial cavity of the zooid, from which they escape to the exterior when fully developed. The larvae of Diplosoma, on the other hand, completing their development embedded in the basal test of the colony, certainly escape less easily, and perhaps only with the dissolution of the parent colony. 


\section{Budding}

Asexual reproduction by budding may, in general, occur at any season and a high proportion of all colonies examined had buds. The process appeared to be less active, however, in August and September, both in the old generation and in the newly established colonies. In Botryllus, as in Diplosoma, exhaustion follows the intense sexual activity of the summer, and reduced asexual reproduction is here the prelude to the death of the old colony. It is surprising that budding activity was not intense in the young colonies of August and September.

\section{SUMMARY}

The populations of Ciona intestinalis, Ascidiella aspersa, Diplosoma listerianum and Botryllus schlosseri in the Old Dock of Ardrossan Harbour, Ayrshire, were studied in 1950 and 195I. Samples taken at intervals of about 4-7 weeks were used to follow growth, the progress of breeding, and the number and duration of generations.

In each species fastest growth was in May, June and early July. There was no growth in winter.

In all the species studied, except Ciona intestinalis for which sufficient data were not obtained, growth was several weeks later in starting in I95I as compared with 1950 .

Each species behaved as an annual, which settled as a larva, grew to sexual maturity, bred, and died, within a period of I2-18 months.

Breeding in each species was confined to a few months in the summer, and took place in the year following that in which the animals settled as larvae. Diplosoma may possibly also have bred at the end of its first summer.

In Diplosoma and Botryllus similar stages in the breeding cycle were several weeks later in I95I than in I950.

In Ascidiella and Ciona critical body sizes were found at which eggs and sperm began to fill the genital ducts. These species are protandrous; after the sperm starts to fill the sperm duct the body grows about $5 \mathrm{~mm}$. before eggs pass into the oviduct.

\section{REFERENCES}

Berrill, N. J., I935. Studies in tunicate development. IV. Asexual reproduction. Phil. Trans. Roy. Soc. London, B, Vol. 225, pp. 327-79.

- 194I. Size and morphogenesis in the bud of Botryllus. Biol. Bull. Woods Hole, Vol. 80, pp. 185-93.

— 1947. The developmental cycle of Botrylloides. Quart. Fourn. Micr. Sci., Vol. 88, pp. 393-407.

I950. The Tunicata. Ray Society, London.

Herdman, W. A., I899. Ascidia. L.M.B.C. Memoirs, Liverpool. 52 pp.

Hŭus, J., 1937. Tunicata: Ascidiaceae. Handb. Zool. Kükenthal und Krumbach. 5, 2nd half, pp. 545-672. 
HuxLey, J. S., I92I. Studies in dedifferentiation. II. Dedifferentiation and resorption in Perophora. Quart. Fourn. Micr. Sci., Vol. 65, pp. 643-97.

LaHILle, F., I890. Recherches sur les Tuhiciers des côtes de France. Toulouse. $330 \mathrm{pp}$.

Lo BIANCO, S., 1909. Notizie biologiche riguardanti specialmente il periodo di maturita sessuale degli animali del golfo di Napoli. Mitt. Zool. Stat. Neapel, Vol. 19, pp. 513-76r.

Orton, J. H., I9I4. Preliminary account of a contribution to an evaluation of the sea. Fourn. Mar. Biol. Assoc., Vol. Io, pp. 312-26.

1920. Sea-temperature, breeding and distribution in marine animals. Fourn. Mar. Biol. Assoc., Vol. I2, pp. 339-66.

RünNSTROM, S., 1936. Die Anpassung der Fortpflanzung und Entwicklung mariner Tiere an die Temperaturverhältnisse verschiedener Verbreitungsgebiete. Bergens. Mus. Arbok, 1936, Nr. 3, 36 pp. 